\title{
Estudo de Caso Sobre Problemas de Comportamento de Uma Criança Inserida em Uma Família Não Tradicional
}

\author{
Patrícia Hobold Meurer \& Cláudia Lúcia Menegatti \\ Universidade Federal do Paraná, Curitiba, Brasil. Universidade Positivo, Curitiba, Brasil
}

\begin{abstract}
RESUMO
As famílias atuais estão passando por processos de mudança e os profissionais de áreas como a psicologia precisam se preparar para trabalhar com esta nova realidade. O objetivo deste estudo foi verificar as relações entre um ajustamento familiar decorrente de uma separação conjugal e os comportamentos problema de uma criança, bem como identificar e descrever intervenções que foram efetivas no processo psicoterapêutico de abordagem comportamental. $\mathrm{O}$ estudo corroborou dados de pesquisas anteriores já que o comportamento problema tinha relação com as adversidades familiares. Além disso, os testes realizados ao fim da intervenção psicoterapêutica mostraram redução no comportamento problema.
\end{abstract}

Palavras-chave: psicoterapia; relações familiares; estilo parental.

\begin{abstract}
Case Study on Behavior Problems of a Child Inserted in a Nontraditional Family

Families today are facing processes of change, and professionals in areas such as psychology must prepare themselves to work with this new reality. The aim of this study was to investigate the relationship between a family adjustment arising from a divorce and a child's behavior problems, as well as identify and describe effective interventions in the psychotherapeutic process with behavioral approach. The study confirmed previous research data, considering that the problem behavior was related to family adversities. Moreover, tests carried out at the end of the psychotherapeutic intervention showed a reduction in problem behavior.
\end{abstract}

Keywords: psychotherapy; family relations; parenting style.

Segundo Conte e Regra (2000), a busca pela terapia infantil ocorre quando o comportamento da criança se intensifica e foge ao controle, à tolerância ou à compreensão dos pais. De acordo com estas autoras, o comportamento inadequado da criança pode ser determinado e mantido por contingências de reforçamento ou governado por regras e traz ou trouxe ganhos para o indivíduo e sua família. Inúmeras razões levam pais ou responsáveis a procurar terapia para suas crianças, Moura (1999) destaca comportamentos agressivos, timidez, enurese noturna e dificuldades de interagir com outras crianças ou familiares.

De acordo com Conte e Regra (2000), relacionados aos comportamentos inadequados da criança, aparecerão determinados padrões comportamentais dos pais.
Bolsoni-Silva e Marturano (2002) afirmam que as famílias estimulam comportamentos antissociais por meio de disciplina inconsistente, pouca interação positiva, pouco monitoramento e supervisão insuficiente das atividades das crianças. Segundo Eddy, Leve e Fagot (2001, citados por Szelbracikowski e Dessen, 2007), famílias cujos pais usam a coerção como principal modo de controle de seus filhos, um processo composto por intrusão aversiva de um dos membros da família na atividade da criança, contra-ataque desta seguido de reforçamento negativo e positivo, aumentam a probabilidade de respostas aversivas futuras da criança. Assim, a qualidade das interações familiares está relacionada ao desenvolvimento saudável da criança. No entanto, as famílias estão passando hoje por processos para os quais se tem poucos modelos, o que

Endereço para correspondência: Patrícia Hobold Meurer - patyhobold@yahoo.com.br 
gera mais estresse para seus membros (Carter \& McGoldrick, 1995).

O sentido de família está em permanente mudança. Para Amazonas, Damasceno, Terto e Silva (2003) o termo 'arranjo familiar' diz respeito aos membros da família, consanguíneos ou não, residentes no mesmo domicílio. Szelbracikowski e Dessen (2007) também definem os limites da família pelos laços de afetividade e intimidade que as pessoas mantêm umas com as outras, não dependendo apenas do parentesco ou do sistema legal que rege as relações familiares. De acordo com Carter e McGoldrick (1995) uma das características atuais da família é a não centralidade da criação dos filhos na vida adulta. Alguns fatores que contribuem para este processo de mudança são o menor índice de natalidade, o aumento da expectativa de vida, a mudança do papel feminino e o crescente índice de divórcios e recasamentos na atualidade. Uma vez que transições familiares, como separações e novas uniões parentais têm sido mais frequentes, elas atraem maior atenção de profissionais da educação, direito e saúde no intuito de compreendê-las e avaliar seus efeitos sobre os envolvidos (Ramires, 2004).

Amazonas et al. (2003) enfatizam que não se sabe ainda quais serão as vantagens ou desvantagens que cada novo arranjo familiar acarretará, principalmente para as crianças, uma vez que são formas recentes, o que denota a necessidade de mais estudos. No entanto, alguns fatores familiares têm sido relacionados ao surgimento e à intensificação dos sintomas psiquiátricos mais comuns em crianças. Para problemas externalizantes, segundo Ferriolli, Marturano e Puntel (2007), alguns fatores de risco são discórdia conjugal severa, desvantagem socioeconômica, tamanho grande da família, criminalidade paterna, transtorno mental da mãe, ruptura da família e estresse familiar, acrescidos de práticas disciplinares intrusivas e severas. Quanto ao divórcio, especificamente, Ramires (2004), enfatiza que se trata de um grande rompimento que afeta não só a família nuclear como também a ampliada. De acordo com Carter e McGoldrick (1995), as associações na família mudam, os membros da família ampliada podem voltar, redefinindo papéis, fronteiras e estrutura hierárquica, sem que haja normas ou apoios sociais para tal, o que torna as mudanças uma fonte de estresse e conflito. Assim, o período pós-divórcio também tem implicações. Entre elas podemos citar a dificuldade do progenitor sozinho de educar e disciplinar os filhos, o que muitas vezes o leva a buscar ajuda de terceiros, como avós ou tios, o que pode também causar conflitos. Outras dificuldades que podem surgir nesta fase são: problemas financeiros, afastamento do grupo social ao qual pertenciam e conflitos dos filhos com membros de uma nova família (Carter \& McGoldrick, 1995).

Em revisão bibliográfica, Marin e Piccinini (2007) encontraram divergências na literatura quanto às implicações das diferentes configurações familiares no desenvolvimento infantil. Algumas pesquisas mostraram que a criança pode se desenvolver sem prejuízos em lares de mães solteiras quando comparada com as crianças dos lares de mães casadas. Por outro lado, parte da literatura aponta para as implicações negativas envolvendo as mães solteiras, principalmente no que se refere às características demográficas, psicológicas e sociais dessas, que tendem a apresentar mais problemas relacionados à baixa renda, maiores índices de estresse e depressão e menor envolvimento, controle e supervisão dos filhos. Deste modo, as adversidades não costumam estar isoladas ou independentes, fazem parte do contexto social, envolvendo fatores políticos, socioeconômicos, ambientais, culturais, familiares e genéticos, sendo que a associação de muitas situações de risco pode dificultar o desenvolvimento, a aquisição de habilidades e o desempenho de papéis sociais (Sapienza \& Pedromônico, 2005).

Assim, a separação conjugal, os novos modelos de família e suas adversidades não devem ser considerados determinantes, mas variáveis que podem influenciar no aparecimento de problemas clínicos infantis. Tendo-se em vista que a tendência atual é de que as famílias continuem em transformação é preciso que as esferas social e profissional estejam preparadas para dar suporte a essas novas famílias. O objetivo deste estudo foi verificar relações entre o ajustamento familiar decorrente de uma separação conjugal e os comportamentos problema de uma criança através do atendimento de um caso. Buscou-se identificar e descrever variáveis relativas às mudanças no contexto familiar que foram importantes para a etiologia da queixa apresentada e identificar e descrever intervenções que foram efetivas no processo terapêutico.

\section{MÉTODO}

A participante foi uma criança de nove anos de idade do sexo feminino, cujos pais eram separados e que foi atendida em uma clínica-escola do estado do 
Paraná. Utilizou-se o instrumento CBCL (Child Behavior Checklist - Achembach, 1991) versão de 4 a 18 anos, que fornece um perfil comportamental da criança a partir do relato dos pais. A análise é feita em programa de computador onde os valores são convertidos em escores de "Funcionamento Global", "Perfil Internalizante" e "Perfil Externalizante" em três níveis de análise: Limítrofe, escores entre 60 e 63, Clínico, escores superiores a 63 e Normal, escores inferiores a 60. Também é avaliada a presença de síndromes cujos escores são: limítrofe (escores 67 a 70); clínico (superior a 70) e normal (inferior a 67).

Foi utilizado também o instrumento IEP (Inventário de Estilos Parentais - Gomide, 2006) composto por 42 questões indicando a frequência com que a pessoa age ou imagina que poderá agir nas situações relacionadas. Os escores podem indicar "Estilo Parental de Risco" (escores 1 a 25), "Estilo Parental Regular, Abaixo da Média" (30-50), "Estilo Parental Regular, Acima da Média" (55-75) e "Estilo Parental Ótimo" (80-99).

A autora da pesquisa elaborou uma folha para Registro do Comportamento Problema com o objetivo de levantar a frequência e a forma do comportamento problema durante uma semana, que também foi usada na coleta de dados. Trata-se de uma tabela simples na qual constam os dias da semana e os períodos do dia (manhã, tarde e noite) na qual a mãe da criança deveria anotar as ocorrências do comportamento problema.

\section{PROCEDIMENTOS}

Realizou-se uma entrevista inicial com a mãe, na qual também foram aplicados os instrumentos citados para a coleta de dados de linha de base. Foram realizadas então 24 sessõescom frequência semanal, estruturadas a partir de uma perspectiva analítico-funcional. Foram mantidos relatos das sessões e a análise funcional dos dados foi realizada após as nove primeiras sessões, cujo caráter foi principalmente investigativo. Após as nove sessões iniciais foram realizadas sessões com o objetivo de desenvolver os repertórios comportamentais deficitários ou comportamentos mais eficientes para o enfrentamento das dificuldades encontradas pela participante nos ambientes escolar e familiar. Ao fim de 22 sessões foram feitas duas sessões para reaplicação dos instrumentos. A análise dos dados foi quantitativa do ponto de vista dos instrumentos utilizados e qualitativa a partir da análise do discurso dos envolvidos.

\section{Histórico da Queixa e de Vida do Cliente}

Luana $^{1}$ era uma menina de 9 anos de idade e estava na $4^{\mathrm{a}}$ série do ensino fundamental quando iniciou a terapia. Sua mãe (Elisa ${ }^{1}$ ) buscou atendimento psicopedagógico após esta apresentar dificuldades escolares sendo que, após avaliação, concluiu-se que tais queixas não decorriam de déficits cognitivos, sendo a menor então encaminhada para atendimento psicoterapêutico. Até os quatro anos de idade Luana residiu com seu pai e sua mãe. Após a separação, residiu por um período apenas com a mãe, que então teve que voltar para a casa de seu pai. No início do atendimento, portanto, Luana residia com sua mãe (32 anos), seu avô materno (60 anos) a esposa do avô (53 anos), uma tia (28 anos) e um tio (20 anos).

Elisa contou que Luana era muito distraída e desligada na escola e que em casa costumava ser nervosa, "briguenta" [sic] e estressada. De acordo com a mãe, tais reações aconteciam quando Luana queria algo e a mãe não permitia, o que a levava a reclamar, chorar, xingar e fazer chantagem emocional. Nestas ocasiões a mãe disse "deixar quieto" (sic) e "deixar falar" (sic). Porém, Elisa relatou que a tia de Luana costumava discutir com a menina nestas ocasiões, pedindo que obedecesse a sua mãe e parasse de reclamar, resmungar e/ou chorar. Luana respondia à tia dando continuidade ao conflito, que costumava ser frequente, além disso, não atendia aos pedidos da tia e perguntava à mãe, que respondia de forma oposta ao que a tia havia falado para se contrapor intencionalmente à tia.

Elisa contou que Luana via raramente seu pai, sendo que este costumava fazer promessas e não cumprir, como prometer visitá-la e não aparecer. A mãe disse que Luana ficava ansiosa, frustrada e triste nestas ocasiões. Contou que Luana não conseguia falar sobre seus sentimentos quando parecia triste. No entanto, quando estava nervosa, Luana brigava, xingava, chorava e fazia chantagens emocionais. Elisa acreditava que Luana tinha que mudar, pois, segundo ela, tais comportamentos aconteciam por qualquer motivo e todos os dias.

\section{MEDIDAS DE LINHA DE BASE}

De acordo com o resultado do CBCL, Luana apresentou escore "clínico" para "Funcionamento Global" (72), "Perfil Internalizante" (69) e "Perfil Externalizante" (71). No que se refere às síndromes avaliadas por este instrumento ela obteve escore "clínico" para 
"Comportamento Agressivo" (73), escore "limítrofe" para "Ansiedade/ Depressão" (70).

$\mathrm{O}$ instrumento IEP foi aplicado em duas versões, para a mãe responder, cujo resultado indicou "Estilo Parental Regular, Abaixo da Média" (escore 40), e para Luana responder, cujo resultado indicou "Estilo Parental Regular, Acima da Média" (escore 60).

$\mathrm{Na}$ folha de Registro do Comportamento Problema Elisa relatou quatro situações nas quais Luana entrou em conflito com os tios. Em duas delas os tios intervieram dando broncas em Luana quando Elisa já fazia isto, então Elisa orientou Luana a não escutá-los. Nas outras duas situações a menina brincava com as amigas e o tio interferiu em sua atividade, gerando brigas.

\section{Descrição do Tratamento: Sessões 1 a 9}

As sessões iniciais tiveram o objetivo de apresentação, formação vínculo, esclarecimento sobre o que é terapia e primeira aplicação dos instrumentos. Nas sessões 4 e 5 buscou-se conhecer a dinâmica familiar. Para tal Luana desenhou o interior de sua casa e contou uma história com o título "um dia na minha casa". Percebeu-se que a TV consumia tempo considerável em seu dia e que Luana participava das conversas de adultos. Nas sessões 6 a 8 foi pedido que Luana desenhasse uma família, uma casa e uma pessoa. A casa desenhada por Luana foi bastante elaborada, com detalhes nas paredes, telhado e fechadura na porta. $\mathrm{Na}$ sessão 9, a terapeuta realizou com Luana um teatro de fantoches encenando situações de conflito em casa. Luana encenou seus comportamentos opositores e percebeu-se que diante de sua insistência a mãe cedia e concedia o que Luana estava pedindo.

\section{ANÁLISE FUNCIONAL}

Luana apresentava muitos excessos comportamentais como chorar, xingar, "ficar brava" e fazer "chantagem emocional". Costumava pedir muitos presentes para a mãe e insistir quando esta negava. Percebeu-se que a mãe de Luana acabava cedendo à sua insistência para que ela a obedecesse, o que funcionava como reforço negativo para o comportamento de ceder da mãe, uma vez que interrompia a estimulação aversiva e reforço positivo para o comportamento de Luana de insistir, já que sinalizava a obtenção do que pedia. Além disso, notou-se que a mãe reagia somente após muita insistência da menina, ou seja, a taxa de resposta de Luana tinha de ser alta e sem interrupção, até que houvesse sinalização de reforço positivo (prometer o brinquedo) ou punição negativa (se Luana não ficasse quieta, não ganharia o brinquedo).

Quanto aos seus déficits comportamentais, Luana tinha poucos amigos, era fechada em ralação ao que sentia quando estava preocupada e triste e tinha dificuldades de solucionar problemas interpessoais, o que sugeria baixo repertório assertivo, de habilidades sociais e de discriminação de sentimentos e de si mesma.

Dentre as variáveis ambientais não facilitadoras podemos citar o fato de Luana morar com adultos jovens e idosos, sendo que algumas falas suas demonstraram quanto ela estava envolvida em seus assuntos, como por exemplo, quando Luana, falando sobre o tio, disse: "ele não estuda nem trabalha, não pára nos empregos" [sic]. Mãe e avô demonstravam seu carinho por Luana através de presentes. A mãe realizava poucas atividades com Luana e elas assistiam muita TV, o que podia aumentar os pedidos de Luana por presentes. A menina parecia ter a seguinte regra: "Se você me presentear, então é legal comigo", visível em algumas falas, como "meu pai é legal, mas não igual minha mãe, ele me dá coisas, mas minha mãe dá mais" [sic].

Os comportamentos inadequados de Luana, portanto, tinham sido reforçados positiva ou negativamente por sua família. Além disso, quando havia punição positiva (ficar de castigo) ela acontecia em conjunto com a sinalização de reforço positivo (fique quieta/ fique de castigo e ganhará o presente). A mãe também não apresentava regras claras no que dizia respeito a "ganhar presentes", ou seja, não havia ocasiões definidas para ganhar presentes (natal/ aniversário) o que dependia apenas da taxa de resposta de insistência de Luana, mantendo-a alta. Luana então por confundir "ganhar presentes" com "ser amada", apresentava também baixa resistência à frustração, o que podia evocar comportamentos de "chantagem emocional".

\section{Descrição do Tratamento: Sessões 10 A 24}

Nas sessões 10 a 12 foi realizada a confecção de um "livrinho de sentimentos" (Moura \& Azevedo, 2000) para discriminação e exposição de sentimentos durante a sessão. Luana demonstrou dificuldade em reconhecer os sentimentos nas figuras, o que confirma a hipótese de baixo repertório de discriminação de sentimentos. Porém, teve mais facilidade para citar exemplos de sua vida. Disse por exemplo sentir "alívio" quando vai a algum lugar bonito, por estar fora 
de casa, pois ela é "muito enjoativa, muito fechada" (sic), o que parece ter relação com o desenho de sua casa feito anteriormente.

Na sessão 13, Luana fez uma tabela com coisas boas e ruins que sua mãe e sua tia faziam em relação a ela, de modo que pudesse identificar que sua tia também fazia coisas boas para ela. A sessão 14 foi realizada com Elisa a fim de investigar sua relação com os irmãos e discutir os papéis exercidos por seus irmãos em relação à Luana. A terapeuta falou sobre como os papéis exercidos pela tia são parecidos com o papel de mãe e explicou que o fato de os papéis não estarem bem definidos poderia gerar confusão para Luana, fazendo com que às vezes a tia fosse obedecida, outras não, sendo isso reforçado por Elisa quando ela desqualificava as ordens da tia.

Nas sessões 15 a 18 foi realizada a confecção de histórias em quadrinhos com temas relativos às brigas de Luana, de forma que ela discriminasse como estas situações se desenvolviam, quais consequências geravam e que inventasse "novas formas de terminar a história", de modo a desenvolver comportamentos de resolução de problemas e assertividade. Na sessão 19 Elisa foi instruída a não ceder diante de comportamentos de insistência de Luana, bem como a manter suas regras, ordens ou decisões. Foi pedido à mãe que diminuísse a frequência com que presenteava Luana e assistiam à $\mathrm{TV}$, para tentar diminuir a demanda de Luana por "ganhar coisas". Ao invés disso pediu-se que mãe oferecesse outro tipo de atenção, como brincar e conversar, para aumentar as interações positivas entre elas e estabelecer novos parâmetros quanto a "ser amada" para Luana.

Na sessão 20 Luana deveria fazer uma escultura em argila e contar uma história. Ela fez uma menina e disse que aquela menina era triste porque queria ter mais amigos e não sabia o que fazer. A terapeuta havia feito uma escultura de um vaso de flor e o usou como metáfora: as amizades são como flores, temos que plantar, cuidar e regar para que elas nasçam, cresçam e fiquem fortes. Luana contou que uma amiga sua a convidou para brincar em sua casa, mas ela não foi para não ficar longe da mãe. A terapeuta sugeriu que Luana conversasse sobre isto com Elisa. Na sessão seguinte ela contou que foi brincar e dormiu na casa de sua amiga.

As sessões 21 a 23 tiveram o objetivo de desligamento de Luana da terapia e reaplicação dos instrumentos de medida, sendo a $24^{a}$ realizada com Elisa para reforçar orientações e mostrar os resultados finais. Na atividade "do que eu mais gostei na terapia?" Luana se desenhou fazendo a atividade de história em quadrinhos e disse ter gostado, pois viu como as coisas aconteciam e o que ela podia fazer. Isto demonstra que houve aumento do repertório de discriminação de Luana.

\section{RESULTADOS}

No segundo preenchimento da folha de Registro do Comportamento Problema Elisa relatou sete ocasiões nas quais Luana agiu adequadamente, como brincar e ajudar a mãe, duas ocasiões em que Luana agiu adequadamente diante de uma ordem da mãe, e outras duas situações em que, diante de uma ordem, ela reclamou e chorou, porém a mãe não cedeu.

$\mathrm{O}$ resultado do CBCL aplicado após encerramento do tratamento de Luana indicou escore "limítrofe" para "Funcionamento Global" e "normal" para "Perfil Internalizante" e "Perfil Externalizante". No que se refere às síndromes avaliadas por este instrumento Luana obteve escore "normal" para todas, inclusive "Comportamento Agressivo" e "Ansiedade/ Depressão". O instrumento IEP indicou, nas versões respondidas pela mãe e por Luana, "Estilo Parental Ótimo". As tabelas abaixo mostram os resultados iniciais e finais dos instrumentos aplicados.

Tabela 1

Comparação entre as Medidas Iniciais e Finais do Instrumento CBCL

\begin{tabular}{lll} 
CBCL & Primeira aplicação & Segunda aplicação \\
Funcionamento global & Clínico (escore 72) & Limítrofe (escore 62) \\
Perfil internalizante & Clínico (escore 69) & Normal (escore 55) \\
Perfil externalizante & Clínico (escore 71) & Normal (escore 59) \\
Comportamento agressivo & Clínico (escore 73) & Normal (escore 61) \\
Ansiedade/ depressão & Limítrofe (escore 70) & Normal (escore 59) \\
\hline
\end{tabular}


Tabela 2

Comparação entre as Medidas Iniciais e Finais do Instrumento IEP

\begin{tabular}{ccc}
\hline IEP & Primeira aplicação & Segunda aplicação \\
Versão respondida pela mãe & $\begin{array}{c}\text { Escore } 40 \text { - Estilo Parental Regular, } \\
\text { Abaixo da Média. }\end{array}$ & Escore 95 - Estilo Parental Ótimo. \\
Versão respondida por Luana & $\begin{array}{c}\text { Escore } 60 \text { - Estilo Parental Regular, } \\
\text { Acima da Média }\end{array}$ & Escore 99 - Estilo Parental Ótimo. \\
\hline
\end{tabular}

\section{DISCUSSÃO}

De acordo com Conte e Regra (2000), o contexto em que a criança nasce e cresce funciona como estabelecedor de determinados tipos de interação entre pais e filhos. As contingências de reforçamento produzidas pela mãe e pela tia de Luana tinham a função de manter e reforçar comportamentos inadequados. A partir da intervenção com a mãe foi possível que esta alterasse suas respostas ao comportamento de Luana e, assim, passasse a ensinar-lhe comportamentos adequados. Os comportamentos problema apresentados estão de acordo com o que Moura (1999) destacou, entre outras razões, para a busca de psicoterapia: comportamentos agressivos, timidez e dificuldades de interagir com outras crianças ou familiares.

No que diz respeito ao tema 'novos modelos de família' este estudo está de acordo com a literatura consultada. A família de Luana incluía parentes consanguíneos e não consanguíneos residentes na mesma casa, sendo que sua mãe obtinha ajuda de familiares para sustentar-lhes. Os problemas relatados como queixa podem ter relação com o que Carter e McGoldrick (1995) assinalam, ou seja, que as famílias estão passando por processos para os quais se tem poucos modelos, o que gera mais estresse para seus membros. Não havia, na família de Luana, regras claras quanto a quem podia exercer autoridade sobre ela e quando poderia ou deveria fazê-lo.

O comportamento agressivo de crianças se desenvolve em famílias cujos pais usam a coerção como principal modo de controle de seus filhos, que tem por consequência aumento de respostas aversivas da criança (Eddy, Leve \& Fagot, 2001, citados por Szelbracikowski \& Dessen, 2007). No caso de Luana, esta prática, realizada por seus tios, evocava comportamentos externalizantes de Luana que eram seguidos de reforçamento negativo (tios ficavam quietos) ou positivo (mãe a defendia e proporcionava outros reforçadores: doces/presentes/atenção).
Houve pouca referência à separação dos pais de Luana por parte dessa e de sua mãe. Isto pode ser devido ao fato de que à época da separação Luana tinha entre 3 e 4 anos. Benetti (2006) ressalta que características específicas da criança como idade, sexo, experiências passadas e capacidade de compreensão, são importantes fatores na determinação dos efeitos que os conflitos conjugais exercerão sobre elas. Assim, o período pós-divórcio foi mais significativo para o surgimento dos problemas comportamentais de Luana.

É necessário destacar que os comportamentos problema de crianças em famílias não tradicionais não se devem apenas aos novos modelos familiares, mas sim a um conjunto de contingências adversas que geralmente ocorrem com maior frequência nessas famílias. No caso apresentado alguns fatores de risco eram: desvantagem socioeconômica, tamanho grande da família, estresse familiar, menor investimento dos pais no desenvolvimento da criança, estimulação de comportamentos antissociais pela família por meio de disciplina inconsistente, pouca interação positiva, pouco monitoramento, supervisão insuficiente das atividades da criança e coerção como modo de controle. Assim, convém enfatizar que tais adversidades também podem ocorrer em famílias tradicionais.

Comparando as medidas iniciais e finais dos instrumentos aplicados constatou-se redução nos comportamentos problema. Percebeu-se que houve melhora nas síndromes Ansiedade/ Depressão e Comportamento Agressivo, avaliadas inicialmente como "limítrofe" (escore 70) e "clínico" (escore 73), respectivamente, sendo que, ao final do tratamento, ambas foram avaliadas no patamar "normal" pelo instrumento CBCL (escores 59 e 61, respectivamente). As escalas de "Perfil Internalizante" e "Perfil Externalizante" passaram de escore "clínico" (69 e 71) para escore "normal" (55 e 59, respectivamente) e a escala "Funcionamento Global" passou de escore "clínico" (72) para "limítrofe" (62) o que também indica melhora. 
No que se refere ao estilo parental da mãe de Luana, este foi avaliado inicialmente como "Regular Abaixo da Média" (escore 40) pelo instrumento IEP na versão respondida pela mãe e "Regular Acima da Média" (escore 60) na versão respondida por Luana. Ao final do tratamento as duas versões indicaram "Estilo Parental Ótimo" (escores 95 e 99), demonstrando a melhora no comportamento materno.

$\mathrm{Na}$ segunda aplicação da folha de Registro do Comportamento Problema Elisa relatou situações positivas, o que não havia acontecido anteriormente. Isto pode significar que aumentaram as interações positivas com Luana e/ ou houve melhora na discriminação da mãe para com comportamentos adequados de Luana. Estima-se que as intervenções realizadas, tanto com Luana quanto com Elisa, contribuíram para a melhora no comportamento de Luana e também no de Elisa, o qual impacta diretamente o comportamento de Luana.

Quanto ao tema estudado, este se configura atual e relevante, já que a as famílias estão passando por grandes processos de mudança, como a redefinição do papel da mulher, a não centralidade da criação de filhos na vida dos pais e o maior índice de divórcios e recasamentos. De acordo com a literatura (Carter \& McGoldrick, 1995) tais processos, para os quais se tem poucos modelos, gera mais estresse para os membros da família e contribui para o surgimento de problemas que estão relacionados ao desenvolvimento e à intensificação de sintomas psiquiátricos comuns em crianças, como, por exemplo, comportamentos externalizantes (Ferriolli, Marturano \& Puntel, 2007). Foi possível observar também que se trata de um tema ainda muito pouco estudado e relatado, principalmente no que diz respeito às publicações analíticocomportamentais. Sugere-se que, dada a notável importância, mais pesquisas e publicações a respeito do tema sejam realizadas. Assim os profissionais da área poderão estar preparados para atender a atualidade dessa demanda e colaborar para tornar estes novos processos menos prejudiciais ao desenvolvimento da criança e da família como um todo.

\section{REFERÊNCIAS}

Achembach, T. M. (1991). Manual for the Child Behavior Checklist/4-18 and profile. Burlington, VT: University of Vermont.

Amazonas, M. C. L. A., Damasceno, P. R., Terto, L. M. S., \& Silva, R. R. (2003). Arranjos familiares de crianças das camadas populares. Psicologia em Estudo, 8, 11-20.

Benetti, S. P. C. (2006). Conflito conjugal: Impacto no desenvolvimento psicológico da criança e do adolescente. Psicologia: Reflexão e Crítica, 19, 261-268.

Bolsoni-Silva, A. T., \& Marturano, E. M. (2002). Práticas educativas e problemas de comportamento: Uma análise à luz das habilidades sociais. Estudos de Psicologia, 7, 227-235.

Carter, B., \& McGoldrick, M. (1995). As mudanças no ciclo de vida familiar: Uma estrutura para terapia familiar (M. A. V. Veronese, Trad.). Porto Alegre: Artes Médicas.

Conte, F. C. S., \& Regra, J. A. G. (2000). Psicoterapia comportamental infantil: Novos aspectos. In E. F. M. Silvares (Ed.), Estudos de caso em psicoterapia clínica comportamental infantil (pp. 79-134). Campinas: Papirus.

Ferriolli, S. H. T., Marturano, E. M., \& Puntel L. P. (2007). Contexto familiar e problemas de saúde mental infantil no programa saúde da família. Revista de Saúde Pública, 41, 251-259.

Gomide, P. I. C. (2006). Inventário de Estilos Parentais: Modelo teórico, manual de aplicação, apuração e interpretação. Petrópolis: Vozes.

Marin, A. H., \& Piccinini, C. A. (2007). Comportamentos e práticas educativas maternas em famílias de mães solteiras e famílias nucleares. Psicologia em Estudo, 12, 13-22.

Moura, C. B. (1999). Encaminhando crianças para a psicoterapia. Pediatria Moderna, 35, 130-134.

Moura, C. B., \& Azevedo, M. R. Z. S. (2000). Estratégias lúdicas para uso em terapia comportamental infantil. In R. C. Wielenska (Ed.), Sobre comportamento e cognição: Vol. 6. Questionando e ampliando a teoria e as intervenções clinicas e em outros contextos (pp. 157-164). Santo André: ESETec.

Ramires, V. R. R. (2004). As transições familiares: A perspectiva de crianças e pré-adolescentes. Psicologia em Estudo, 9, 183193.

Sapienza, G., \& Pedromônico, M. R. M. (2005). Risco, proteção e resiliência no desenvolvimento da criança e do adolescente. Psicologia em Estudo, 10, 209-216.

Szelbracikowski, A. C., \& Dessen, M. A. (2007). Problemas de comportamento exteriorizado e as relações familiares: Revisão de literatura. Psicologia em Estudo, 12, 33-40.

\section{Nota:}

1 Nomes aleatórios/fictícios. 
